\title{
Competition between Hydrogen Evolution and Carbon Dioxide Reduction on Copper Electrodes in Mildly Acidic Media
}

\author{
Hideshi Ooka, ${ }^{\dagger,+}$ Marta C. Figueiredo, ${ }^{\S}$ and Marc T. M. Koper ${ }^{*},(0)$ \\ ${ }^{\dagger}$ Department of Applied Chemistry, The University of Tokyo, 7-3-1, Hongo, Bunkyo-ku, Tokyo 113-8656, Japan \\ ${ }^{\ddagger}$ Biofunctional Catalyst Research Team, Center for Sustainable Resource Science, RIKEN, 2-1, Hirosawa, Wako, Saitama 351-0198, \\ Japan \\ ${ }^{\S}$ Leiden Institute of Chemistry, Leiden University, 2300 RA, Leiden, The Netherlands
}

\section{Supporting Information}

ABSTRACT: Understanding the competition between hydrogen evolution and $\mathrm{CO}_{2}$ reduction is of fundamental importance to increase the faradaic efficiency for electrocatalytic $\mathrm{CO}_{2}$ reduction in aqueous electrolytes. Here, by using a copper rotating disc electrode, we find that the major hydrogen evolution pathway competing with $\mathrm{CO}_{2}$ reduction is water reduction, even in a relatively acidic electrolyte ( $\mathrm{pH} 2.5$ ). The mass-transport-limited reduction of protons takes place at potentials for which there is no significant competition with $\mathrm{CO}_{2}$ reduction. This selective inhibitory effect of $\mathrm{CO}_{2}$ on water reduction, as well as the difference in onset potential even after correction for local $\mathrm{pH}$ changes, highlights the importance of differentiating between water reduction and proton reduction pathways for hydrogen evolution. In-situ FTIR spectroscopy indicates that the adsorbed $\mathrm{CO}$ formed during $\mathrm{CO}_{2}$ reduction is the primary intermediate responsible for inhibiting the water reduction process, which may be one of the main mechanisms by which copper maintains a high faradaic efficiency for $\mathrm{CO}_{2}$ reduction in neutral media.

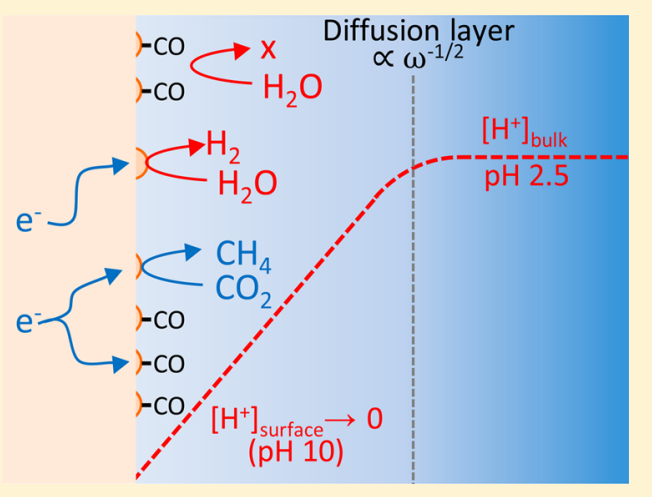

\section{INTRODUCTION}

The electrochemical reduction of $\mathrm{CO}_{2}$ has received much attention in recent years ${ }^{1-12}$ as a potential method to produce useful chemicals from an abundant carbon source and renewable electricity. Target products include hydrocarbons such as methane $e^{4,5,10}$ and ethylene, ${ }^{5,6,10}$ or chemical feedstock such as formate, ${ }^{7,8}$ aldehydes, ${ }^{8,9}$ and alcohols ${ }^{9}$ which may be used for further chemical synthesis. This would effectively shift the carbon source from fossil fuels to (atmospheric) $\mathrm{CO}_{2}$, which would greatly enhance the sustainability and carbonneutrality of modern society. However, one major challenge for $\mathrm{CO}_{2}$ reduction in aqueous electrolytes is the loss of faradaic efficiency due to the simultaneous evolution of hydrogen (HER, hydrogen evolution reaction), ${ }^{13,14}$ which may occur either through the reduction of protons $\left(2 \mathrm{H}^{+}+2 \mathrm{e}^{-} \rightarrow \mathrm{H}_{2}\right)$ or through the reduction of the solvent molecule itself $\left(2 \mathrm{H}_{2} \mathrm{O}\right.$ $\left.+2 \mathrm{e}^{-} \rightarrow \mathrm{H}_{2}+2 \mathrm{OH}^{-}\right)$. It is therefore of primary interest to uncover how the faradaic efficiency of $\mathrm{CO}_{2}$ reduction can be increased with respect to HER.

Recent reports have attempted to rationalize the preferred pathways based on the calculation of onset potentials by density functional theory (DFT) ${ }^{15,16}$ By focusing on the reaction step with the most negative potential in a given pathway, the onset potential of HER and $\mathrm{CO}_{2}$ reduction can be calculated based on the binding energies of $\mathrm{H}$ and $\mathrm{CO}_{2}$ related intermediates. For example, Durand et al. have found $\mathrm{Cu}$ (211) facets to be favored compared to $\mathrm{Cu}(111)$ and (100) facets ${ }^{15}$ based on a combined effect of a smaller thermodynamic driving force necessary for $\mathrm{CO}_{2}$ reduction and a larger driving force necessary for HER.

While the thermodynamic model is a powerful approach, it does not currently account for the two pathways of HER. They are identical within this framework due to the assumption that proton/hydroxide transfer is always accompanied by concerted electron transfer, meaning that $\mathrm{pH}$ is not an explicit parameter in the model. In reality, however, water reduction is expected to dominate over proton reduction at higher $\mathrm{pH}$ where the proton concentration is low. This effect may take place even in relatively acidic electrolytes because the local proton concentration at the cathode decreases during $\mathrm{HER}^{18}$ and $\mathrm{CO}_{2}$ reduction due to slow mass transport. ${ }^{19,20}$ The onset potential and kinetics of the two pathways may also change with $\mathrm{pH}$, as is, for instance, well-known for HER on platinum electrodes. $^{21-23}$ In the remainder of this article, we will refer to "proton reduction" as hydrogen evolution from acidic media showing a direct dependence on proton concentration, and to "water reduction" as hydrogen evolution from neutral media

Special Issue: Fundamental Interfacial Science for Energy Applications

Received: March 1, 2017

Revised: April 26, 2017

Published: April 28, 2017 
showing no direct dependence on proton concentration. We realize that the actual state of the proton or proton donor may be more complex. The importance of the proton source in hydrogen evolution has been demonstrated recently in organic solvents by Jackson et al., ${ }^{24}$ who showed that steric effects of the proton donor drastically affected the HER Tafel slope, even when the $\mathrm{p} K_{\mathrm{a}}$ of the proton donors were similar. Differentiating the proton source is especially important from the viewpoint of discussing the competition of $\mathrm{HER}$ and $\mathrm{CO}_{2}$ reduction because the presence of $\mathrm{CO}_{2}$ may affect the two HER pathways differently. Furthermore, $\mathrm{CO}_{2}$ may act as or form $\mathrm{pH}$ buffers, ${ }^{19,20}$ adsorbates, ${ }^{17}$ and proton donor/acceptors ${ }^{25}$ during the reaction, all of which may interact differently with the HER pathway. Therefore, it is important to study the effects of $\mathrm{CO}_{2}$ on the two pathways of HER by explicitly taking into account the effect of mass transport and local $\mathrm{pH}$ at the electrode. ${ }^{19,20}$

Here, we have studied the competition of $\mathrm{CO}_{2}$ reduction with the overall HER rate from the reduction of both water and protons on a copper electrode, which is the most extensively studied electrocatalyst for $\mathrm{CO}_{2}$ reduction. The usage of a rotating disc electrode ( $\mathrm{RDE}$ ) system has allowed us to systematically change the flux of protons to the electrodeelectrolyte interface, which in turn allows estimations of the local $\mathrm{pH}$. Our results show that $\mathrm{CO}_{2}$ reduction does not significantly interfere with proton reduction in acidic electrolytes. Instead, the HER pathway that competes with $\mathrm{CO}_{2}$ reduction is the reduction of water. FTIR measurements suggest that this selective inhibition takes place through adsorbed $\mathrm{CO}$. In addition to the different interactions with $\mathrm{CO}_{2}$ reduction, the onset potential of the two HER pathways is different even after compensating for local $\mathrm{pH}$ changes. These results highlight the importance of explicitly differentiating between HER from proton reduction and water reduction, and provide new insight into how copper reduces $\mathrm{CO}_{2}$ efficiently by suppressing HER.

\section{EXPERIMENTAL SECTION}

All electrolytes were prepared using HPLC $(=99.0 \%)$ grade sodium perchlorate monohydrate (Fluka, 7791-07-3) and $60 \mathrm{wt} \%$ perchloric acid (Merck, 7601-90-3), and were used without further purification. A phosphate stock solution ( $\mathrm{pH} 2.5$; total concentration of phosphate ions, $10 \mathrm{M}$ ) was made from $\mathrm{NaH}_{2} \mathrm{PO}_{4} \cdot \mathrm{H}_{2} \mathrm{O}$ (Merck, 10049-21-5) and $\mathrm{H}_{3} \mathrm{PO}_{4}$ (Merck,7664-38-2), and was diluted as necessary with the perchlorate solution to yield an electrolyte with the desired buffer concentration. The HCHO used (Sigma-Aldrich, 50-00-0) contained ca. $10-15$ wt $\% \mathrm{CH}_{3} \mathrm{OH}$ as a stabilizing agent. All electrolytes were bubbled with the appropriate gas $\left(\mathrm{Ar}, \mathrm{CO}\right.$, or $\left.\mathrm{CO}_{2}\right) 30 \mathrm{~min}$ prior to the electrochemical measurement. The $\mathrm{pH}$ change due to switching from $\mathrm{Ar}$ atmosphere to $\mathrm{CO}_{2}$ is negligible, based on $\mathrm{pH}$ meter readings $(\Delta \mathrm{pH}<0.05)$ and the identical height of the diffusion plateau of HER during the CVs. The $\mathrm{pH}$ value of 2.5 was intentionally chosen because the proton concentration is high enough to ensure the $\mathrm{pH}$ does not change upon $\mathrm{CO}_{2}$ bubbling but low enough that the diffusion plateau for proton reduction can be observed at low current densities. The copper rotating disc electrode was polished to a mirror finish using alumina paste $(1.0 \mu \mathrm{m}, 0.3 \mu \mathrm{m}$, and $0.05 \mu \mathrm{m})$ and then sonicated before use. The copper thin film used for the FTIR measurements, which were performed with a Bruker Vertex $80 \mathrm{~V}$ IR spectrophotometer (with an MCT detector and p-polarized light, in the external reflection configuration), was deposited on the silicon prism via sputtering and was used without further cleaning. No electropolishing was conducted in any of the experiments. The spectra correspond to an average of 100 scans with $8 \mathrm{~cm}^{-1}$ resolution. The reference and counter electrodes were a commercial RHE (Gaskatel Hydroflex) and platinum wire, respectively, with the exception of the FTIR measurements where we employed a $\mathrm{Ag} / \mathrm{AgCl}$ sat. reference electrode due to the cell configuration. All potentials are reported versus the RHE. Ohmic resistance was compensated during the measurements using the IVIUM potentiostat software (Ivium Soft) for the CVs and after the measurements for the FTIR measurements.

\section{RESULTS AND DISCUSSION}

Figure 1 shows a cyclic voltammogram (CV) of a polycrystalline copper rotating disc electrode $(\mathrm{RDE})$ in an Ar-saturated

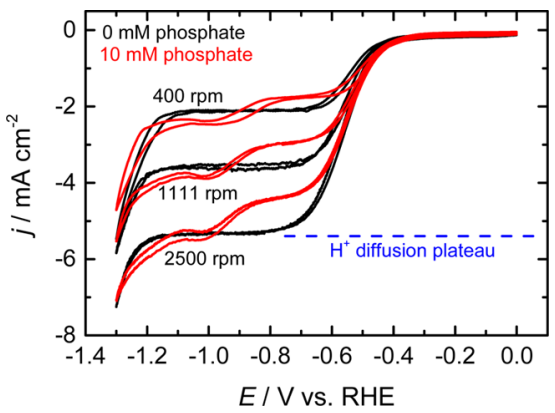

Figure 1. CVs of a polycrystalline copper RDE with (red) and without (black) $10 \mathrm{mM}$ phosphate in a $0.1 \mathrm{M} \mathrm{NaClO}_{4}$ solution $(\mathrm{pH} 2.5)$ under Ar-saturated conditions. Scan rate: $50 \mathrm{mV} / \mathrm{s}$.

$0.1 \mathrm{M} \mathrm{NaClO}$ e electrolyte ( $\mathrm{pH}$ 2.5). In the case of an unbuffered electrolyte (black lines), the reduction current at ca. $-0.5 \mathrm{~V}$ vs RHE (Reversible Hydrogen Electrode) leads to a plateau current which correlates with the square root of the rotation rate, indicating mass transport limitation. ${ }^{27}$ We ascribe this current to hydrogen evolution from proton reduction, ${ }^{23}$ where the notation "proton" refers collectively to all chemical species which can be considered solvated forms of a hydrogen/ proton nucleus. The current which increases from ca. $-1.2 \mathrm{~V}$ vs RHE, on the other hand, is independent from proton mass transport. As the only other proton (hydrogen nucleus) donor in this system is the water molecule itself (the $\mathrm{p} K_{\mathrm{a}}$ of perchlorate is -15 , indicating that it is deprotonated under our experimental conditions ${ }^{26}$ ), we assign this current to HER from water reduction. The mass transport limitation of protons leads to a discrepancy between the $\mathrm{pH}$ at the surface of the electrode and the bulk electrolyte, which makes accurate determination of the actual overpotential for water reduction difficult. Regardless of the true overpotential, however, the marked difference in the apparent onset potential between proton reduction and water reduction is an observation which highlights the importance of explicitly distinguishing between the two pathways. The RDE configuration allows precise control over the diffusion layer thickness and the mass transport flux of protons. Therefore, the surface $\mathrm{pH}$ relative to the bulk electrolyte at a specific potential can be estimated based on the ratio of the total current density at the potential to the plateau current density $\left(\frac{j_{\text {total }}}{j_{\text {lim }} \mid}\right.$ see modeling section for details). For example, the local $\mathrm{pH}$ at -0.8 $\mathrm{V}$ is estimated to be c.a. 4.5 because the current density of proton reduction at $-0.8 \mathrm{~V}$ corresponds to $99 \%$ of the limiting current. As the current of proton reduction is defined by mass transport, the proton concentration at the surface of the electrode can be estimated to be $1 \%$ of that in the bulk electrolyte ( $\mathrm{pH} 4.5)$. CVs with an RHE potential scale which has been corrected for local $\mathrm{pH}$ changes will be presented later in this study.

It should be noted that the change in local $\mathrm{pH}$ is also manifested in a buffered solution, as shown by the red lines in 
Figure 1. The presence of a plateau current can be seen even after the addition of $10 \mathrm{mM}$ phosphate, indicating that the redox active species (protons) are depleted at the electrode surface (the plateau current at ca. $-0.8 \mathrm{~V}$ is smaller than that in the unbuffered case due to the slightly higher $\mathrm{pH}$ in the buffered solution). The gradual increase of the $\mathrm{pH}$ at the vicinity of the electrode can also be observed from the increase in the plateau current at c.a. $-1.0 \mathrm{~V}$. When the $\mathrm{pH}$ at the electrode surface becomes more alkaline than the $\mathrm{p} K_{\mathrm{a} 2}$ of phosphate (7.2), the phosphate species at the electrode are deprotonated to form $\mathrm{HPO}_{4}^{-}$species. This allows the transport of $\mathrm{H}_{2} \mathrm{PO}_{4}^{-}$from the bulk electrolyte to make an additional contribution to the total proton flux. Such an effect is not unique to phosphate but may occur with other buffer molecules such as bicarbonate species, if the concentration and buffering capacity is sufficiently high, as will be discussed later in the article based on a quantitative model.

The transition of the HER pathway from proton reduction to water reduction in Figure 1 occurs at approximately $-5.6 \mathrm{~mA}$ / $\mathrm{cm}^{2}$ at $2500 \mathrm{rpm}$, where the mass transport of protons becomes insufficient. However, the limiting current is linearly proportional to the concentration of protons, and therefore, the water reduction pathway will become increasingly important in more alkaline conditions. The limiting current of protons at $\mathrm{pH} 7$ is approximately $0.2 \mu \mathrm{A} / \mathrm{cm}^{2}$ even at $2500 \mathrm{rpm}$, indicating the majority of the hydrogen detected in studies using stationary electrodes in mildly alkaline electrolytes is likely to be derived from water reduction.

Figure 2 shows the $\mathrm{CVs}$ measured in a $\mathrm{CO}_{2}$-saturated electrolyte for different values of the disc rotation rate.

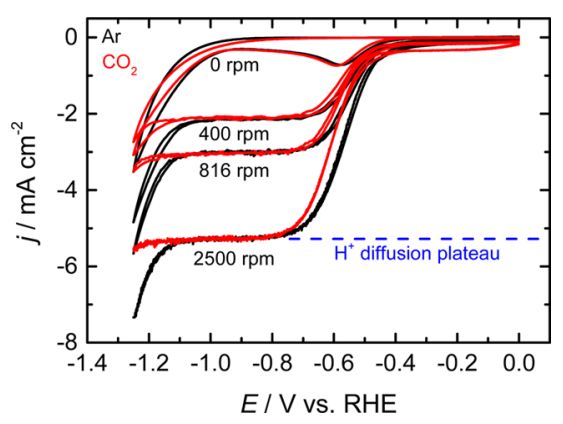

Figure 2. CVs of a polycrystalline copper $\mathrm{RDE}$ at various rotation rates in $0.1 \mathrm{M} \mathrm{NaClO}_{4}$ solution ( $\mathrm{pH} 2.5$ ) saturated with $\mathrm{Ar}$ (black lines) and $\mathrm{CO}_{2}$ (red lines). No bulk $\mathrm{pH}$ change was observed upon $\mathrm{CO}_{2}$ saturation as evidenced by the identical height of the limiting current. Scan rate: $50 \mathrm{mV} / \mathrm{s}$.

Compared to the Ar-saturated solution (black lines), the onset of the proton reduction current in $\mathrm{CO}_{2}$-saturated solution is slightly shifted to a more negative potential. In contrast, a more pronounced suppression is observed for the water reduction current at potentials more negative than $-1.2 \mathrm{~V}$, suggesting that $\mathrm{CO}_{2}$ interferes more strongly with the water reduction process than with proton reduction. This suppression in activity is not due to impurities in the electrolyte, as it does not occur in an Ar atmosphere. Buffering effects are also minimal, as no increase in proton flux could be observed, even when the $\mathrm{pH}$ at the electrode surface becomes more alkaline than the $\mathrm{pK}_{\mathrm{a} 1}$ of $\mathrm{H}_{2} \mathrm{CO}_{3}$ (3.6). This is most likely due to the low buffer capacity arising from the low solubility of $\mathrm{CO}_{2}$ in acidic solutions.
In order to gain insight into the origin of this selective inhibitory behavior, CVs were measured in an electrolyte solution saturated with $\mathrm{CO}$ (Figure $3 \mathrm{~A}$ ). $\mathrm{CO}$ is the two-
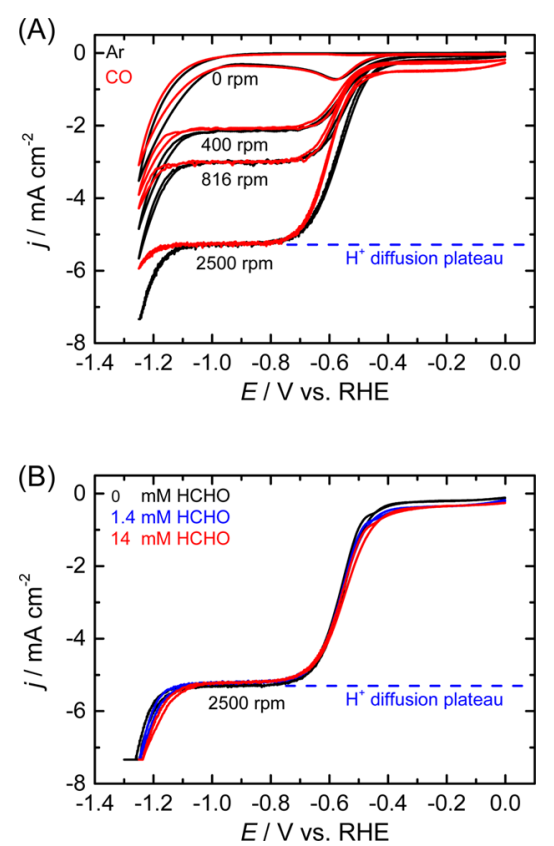

Figure 3. CVs of a polycrystalline copper electrode before (black) and after (red and blue) the addition of reduced forms of $\mathrm{CO}_{2}$ to a $0.1 \mathrm{M}$ $\mathrm{NaClO}_{4}$ electrolyte ( $\mathrm{pH}$ 2.5). (A) Ar-saturated solution resaturated with $\mathrm{CO}$. (B) HCHO addition in Ar atmosphere. Scan rate: $50 \mathrm{mV} / \mathrm{s}$.

electron reduction product of $\mathrm{CO}_{2}{ }^{28,29}$ and has been proposed to be the inhibitor of HER due to site-blocking effects. ${ }^{30,31}$ However, similar to the case with $\mathrm{CO}_{2}$, we find that the proton reduction process is not inhibited by the presence of $\mathrm{CO}$ as much as the water reduction process. The different interactions between the two pathways of HER with $\mathrm{CO}_{2}$ reduction further emphasizes the importance of explicitly distinguishing the substrate molecule for HER. The inhibitory effect was not observed when further reduced forms of $\mathrm{CO}_{2}$ such as $\mathrm{HCHO}$ and $\mathrm{CH}_{3} \mathrm{OH}$ were present in the electrolyte (Figure 3B). Although a portion of $\mathrm{HCHO}$ is known to hydrate to methanediol in water, these results nonetheless show that excessively reduced adsorbates cannot reproduce the inhibitory effects of $\mathrm{CO}_{2}$ or $\mathrm{CO}$ toward water reduction. These observations suggest the origin of the inhibitory effect comes primarily from $\mathrm{CO}$ adsorbed on the surface of copper.

The inhibitory effects of $\mathrm{CO}$ and $\mathrm{CO}_{2}$ on water reduction behave similarly with respect to the rotation rate, as shown in Figure 4. As the proton reduction rate is represented by its limiting current density, subtracting this limiting current from the total reduction current in either $\mathrm{Ar}$ atmosphere or $\mathrm{CO}_{2} / \mathrm{CO}$ atmosphere is expected to express the sum of the reaction rates for water reduction and $\mathrm{CO}_{2}$ (or $\mathrm{CO}$ ) reduction. Therefore, comparing this reduction current at a potential in the water reduction regime in $\mathrm{CO}$ or $\mathrm{CO}_{2}$ atmosphere to the reduction current in $\mathrm{Ar}$ atmosphere illustrates to which extent $\mathrm{CO}$ and $\mathrm{CO}_{2}$ inhibit water reduction at different mass transport rates. If the $\mathrm{CO}$ or $\mathrm{CO}_{2}$ reduction current is negligible, the $y$-axis represents the rate of water reduction in $\mathrm{CO}_{2}$ or $\mathrm{CO}$ atmosphere relative to that in $\mathrm{Ar}$. In both cases, water reduction is inhibited drastically from 0 to $500 \mathrm{rpm}$, whereas higher rotation rates have a less significant effect. The strong inhibition 


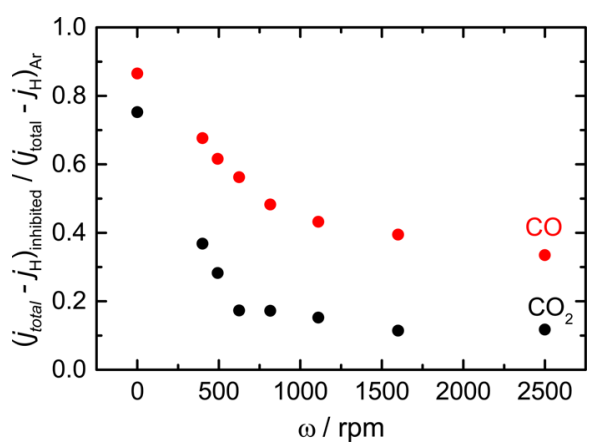

Figure 4. Inhibitory effects of $\mathrm{CO}_{2}$ (black) and $\mathrm{CO}$ (red) plotted with respect to the rotation rate of the copper RDE. The $y$-axis is the current density in each atmosphere normalized by that in an $\mathrm{Ar}$ saturated atmosphere. A lower value of the ratio plotted on the $y$-axis implies a stronger inhibition of HER from water reduction. The limiting current density corresponding to the rate of proton reduction $j_{\mathrm{H}}$ was subtracted to highlight the inhibition of the water reduction pathway. Ratios of current density values were calculated at $-1.25 \mathrm{~V}$ vs RHE.

at low rotation rates $(\omega<500 \mathrm{rpm})$ should be due to the increased coverage of $\mathrm{CO}$ on the copper surface due to the efficient transport of $\mathrm{CO}$ and $\mathrm{CO}_{2}$. This effect apparently saturates at higher rotation rates presumably because the $\mathrm{CO}$ coverage reaches a constant value. The current density in the case of CO-saturated electrolyte is larger than that in the $\mathrm{CO}_{2}$ saturated electrolyte. This may be due to $\mathrm{CO}_{2}$ reduction generating other inhibitory adsorbates such as formate. Another possibility is the difference in the $\mathrm{CO}$ coverage in different atmospheres, as a result of the different solubilities of $\mathrm{CO}_{2}$ and $\mathrm{CO}$ in water. In any case, further experiments would be necessary to uncover the difference in inhibitory effects.

In order to confirm that the inhibitory effect of $\mathrm{CO}_{2}$ reduction on HER arises from adsorbed $\mathrm{CO}$, in situ FTIR (Fourier transform infrared) spectra were measured in an ATRIR (attenuated total reflection infrared) configuration (Figure 5 ). With the spectrum at $0 \mathrm{~V}$ as the reference, the IR band at ca. $2050 \mathrm{~cm}^{-1}$, which we assign to adsorbed $\mathrm{CO},{ }^{31}$ increases from $-0.8 \mathrm{~V}$ during the negative potential step and remains until $-1.2 \mathrm{~V}$. Although $\mathrm{CO}$ is known to be further reduced at negative potentials, ${ }^{28,29}$ the constant $\mathrm{CO}$ coverage at water

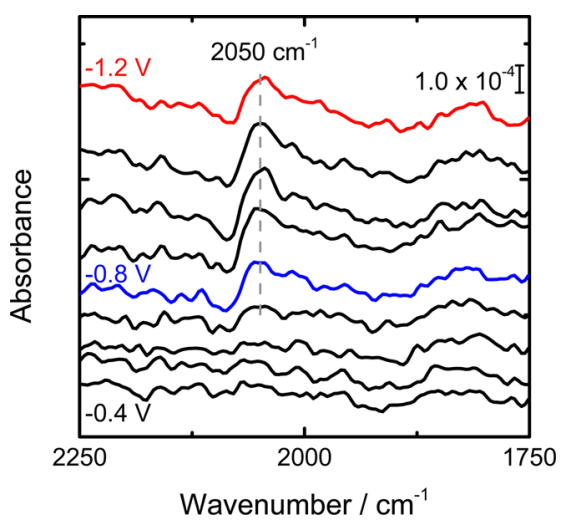

Figure 5. FTIR spectra of a polycrystalline copper electrode in $0.1 \mathrm{M}$ $\mathrm{NaClO}_{4}$ electrolyte ( $\mathrm{pH} 2.5$ ). The copper film was deposited on the silicon prism by sputtering. The solution was saturated with $\mathrm{CO}_{2}$ for $30 \mathrm{~min}$, after which the reference spectrum was measured at $0 \mathrm{~V}$. The spectra were measured from $-0.4 \mathrm{~V}$ to $-1.2 \mathrm{~V}$ in $0.1 \mathrm{~V}$ intervals. reduction potentials $(E \sim-1.2 \mathrm{~V})$ indicates that an inhibitory interaction such as site blocking or a shift in the hydrogen binding energy ${ }^{32}$ is possible. The coverage of $\mathrm{CO}_{\mathrm{ads}}$ at potentials less negative than $-0.8 \mathrm{~V}$ appears to be too low to have a significant inhibitory influence on proton reduction. The interaction between $\mathrm{CO}$ and copper is known to be favorable for $\mathrm{CO}_{2}$ reduction based on theoretical ${ }^{15,16}$ and experimen$\operatorname{tal}^{5,6,10}$ observations that $\mathrm{CO}$ can adsorb and desorb on copper efficiently. However, such an intermediate binding energy also allows the copper surface to maintain a high $\mathrm{CO}$ coverage during $\mathrm{CO}_{2}$ reduction, which enhances the faradaic efficiency with respect to HER. We have also observed the growth of vibrational bands 1435 and $1280 \mathrm{~cm}^{-1}$ at potentials more negative than $-0.9 \mathrm{~V}$ (see Figure $\mathrm{S} 1$ in the Supporting Information). These bands resemble the IR bands of bicarbonate, in accord with the depletion of protons at the electrode surface. $^{33}$

The idea of HER being inhibited by adsorbed $\mathrm{CO}$ has been proposed in the past. ${ }^{17,30}$ However, it should be noted that previous literature has not explicitly differentiated between the two HER pathways, which show marked differences in terms of apparent onset potentials (Figures 1-3) and interaction with adsorbed $\mathrm{CO}$ (Figure 5). As the $\mathrm{pH}$ change at the surface of the electrode would lead to an overestimation of the difference in overpotential, it is important to compensate for the change of $\mathrm{pH}$ for a better comparison. By modeling the local $\mathrm{pH},{ }^{18-20}$ we can estimate the true onset potential of the water reduction reaction and also show that $\mathrm{CO}_{2}$ buffering effects should indeed be negligible under our conditions.

As Auinger et al. have shown, ${ }^{18}$ the amount of protons consumed and hydroxide ions generated at the electrode due to HER corresponds to the mass transport flux of each ion under steady-state conditions, which should apply to our experiments. Therefore, the total current density $\left(j_{\text {total }}\right)$ can be expressed using the mass transport fluxes of $\mathrm{H}^{+}\left(J_{H}\right)$ and $\mathrm{OH}^{-}\left(J_{\mathrm{OH}}\right)$ as follows:

$$
\begin{aligned}
& j_{\text {total }}=F\left(\left.J_{H}\right|_{x \rightarrow 0}-\left.J_{O H}\right|_{x \rightarrow 0}\right) \\
& =-F D_{H} \frac{[H]_{b}-[H]_{s}}{\delta_{H}}+F D_{O H} \frac{[O H]_{b}-[O H]_{s}}{\delta_{O H}}
\end{aligned}
$$

where $x$ is the distance from the electrode, $F$ is the faraday constant, $[\mathrm{X}]$ is the concentration of $\mathrm{X}, D_{X}$ is the diffusion coefficient, and $\delta_{\mathrm{X}}$ is the diffusion layer thickness. Subscripts $b$ and $s$ indicate bulk and surface values, and subscripts $\mathrm{H}$ and $\mathrm{OH}$ indicate protons and hydroxyl ions, respectively. $\delta_{\mathrm{H}}$ and $\delta_{\mathrm{OH}}$ depend on the rotation rate of the $\mathrm{RDE}$ following the Levich equation. Normalizing $j_{\text {total }}$ by the absolute value of the limiting current density ${ }^{23}$

$$
\left|j_{\lim }\right|=F D_{H} \frac{[H]_{b}}{\delta_{H}}
$$

generates a rotation-rate independent parameter.

$$
\frac{j_{\text {total }}}{\left|j_{\lim }\right|}=-\frac{[H]_{b}-[H]_{s}}{[H]_{b}}+\frac{D_{O H} / D_{H}}{\delta_{O H} / \delta_{H}} \frac{[O H]_{b}-[O H]_{s}}{[H]_{b}}
$$

Finally, assuming that water hydrolysis is in equilibrium allows for the substitution of hydroxide ion concentrations using the proton concentrations and the water dissociation constant $K_{\mathrm{w}}$. The local proton concentration at the electrode can therefore be expressed as 


$$
[H]_{s}=\frac{-\alpha+\sqrt{\alpha^{2}+4\left(\frac{D_{O H} \delta_{H}}{D_{H} \delta_{O H}}\right) K_{w}}}{2}
$$

where

$$
\alpha=-[H]_{b}+\frac{D_{O H} \delta_{H}}{D_{H} \delta_{O H}} \frac{K_{w}}{[H]_{b}}-\frac{j_{\text {total }}}{\left|j_{\lim }\right|}[H]_{b}
$$

This equation allows for the estimation of the surface $\mathrm{pH}$ based on the normalized current density, assuming that water dissociation is the only solution equilibrium that protons or hydroxide ions are involved in. An important implication from these derivations is that the surface $\mathrm{pH}$ is a function of $\frac{j_{\text {total }}}{\left.\right|_{\lim } \mid}$, not the raw rotation rate. This is because although a faster rotation rate generates a larger proton mass transport flux, the local $\mathrm{pH}$ is dictated based on the balance with the consumption rate which is represented by the current density. Therefore, $\frac{j_{\text {total }} \mid}{\left|j_{\text {lim }}\right|}$ can be interpreted as a normalized rotation rate, which shows the ratio of proton supply and consumption.

Figure 6 shows the results of the modeling based on eq 4 . It can be seen that when the current density approaches the

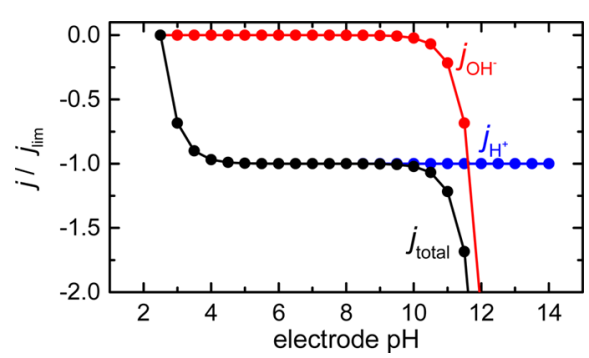

Figure 6. Estimation of the normalized current density based on the $\mathrm{pH}$ near the electrode surface ("electrode $\mathrm{pH}$ ") (eq 4). The first and second terms of eq 4 are shown in blue and red, and their total is shown in black. The diffusion layer thicknesses were calculated from the Levich equation using a kinematic viscosity of $1 \mathrm{~cm}^{2} / \mathrm{s}, D_{H}=9.31$ $\times 10^{-5}\left[\mathrm{~cm}^{2} / \mathrm{s}\right]$, and $D_{O H}=5.27 \times 10^{-5}\left[\mathrm{~cm}^{2} / \mathrm{s}\right] .{ }^{18}$ The rotation rate plays no role due to the normalization with the limiting current.

limiting current, the surface $\mathrm{pH}$ exhibits a sharp change from $\mathrm{pH} 4$ to 10 in a narrow current range. The increase of $\mathrm{pH}$ at the electrode surface at current densities greater than the limiting current is sufficiently high for carbonic acid to deprotonate and generate bicarbonate and carbonate ions. This suggests that a $\mathrm{pH}$ buffering effect may be present even in unbuffered electrolytes if the mass transport of protons is slow compared to the rate of HER. Therefore, in a $\mathrm{CO}_{2}$ saturated electrolyte, it becomes necessary to model the electrode $\mathrm{pH}$ assuming the presence of a buffer molecule.

The effect of buffer ions in the solution and their effect on local $\mathrm{pH}$ can be modeled using an approach similar to the one above. Assuming a buffer ion with the acid-base equilibrium ( $\mathrm{HA} \leftrightarrows \mathrm{H}^{+}+\mathrm{A}^{-}$, equilibrium constant $K_{\mathrm{a}}$ ), the difference between bulk $\mathrm{pH}$ and surface $\mathrm{pH}$ can be suppressed because the flux of buffer molecules makes an additional contribution to the net proton flux. In steady state, the following equation should hold:

$$
\left.J_{H A}\right|_{x \rightarrow 0}+\left.J_{A}\right|_{x \rightarrow 0}=0
$$

which is equivalent to

$$
D_{H A} \frac{[H A]_{b}-[H A]_{s}}{\delta_{H A}}=-D_{A} \frac{[A]_{b}-[A]_{s}}{\delta_{A}}
$$

Given the acid-base equilibrium between $\mathrm{HA}$ and $\mathrm{A}^{-}$, this leads to the following solution for $[\mathrm{A}]_{\mathrm{S}}$ :

$$
[A]_{s}=\frac{\beta[H]_{b}+1}{\beta[H]_{s}+1}[A]_{b}
$$

where

$$
\beta=\frac{D_{H A}}{D_{A}} \frac{\delta_{A}}{\delta_{H A}} \frac{1}{K_{a}}
$$

The current density in a buffered solution is given by

$$
j_{\text {total }}=F\left(\left.J_{H}\right|_{x \rightarrow 0}-\left.J_{O H}\right|_{x \rightarrow 0}-\left.J_{A}\right|_{x \rightarrow 0}\right)
$$

so that the normalized current density can be expressed as

$$
\begin{aligned}
\frac{j_{\text {total }}}{\left|j_{\lim }\right|}= & -\frac{[H]_{b}-[H]_{s}}{[H]_{b}}+\frac{D_{O H} / D_{H}}{\delta_{O H} / \delta_{H}} \frac{[O H]_{b}-[O H]_{s}}{[H]_{b}} \\
& +\frac{D_{A} / D_{H}}{\delta_{A} / \delta_{H}} \frac{[A]_{b}-[A]_{s}}{[H]_{b}}
\end{aligned}
$$

The numerical solution to this equation at various buffer concentrations is shown in Figure 7, modeled for a bulk $\mathrm{pH}$ of 2.5 and using the diffusion constants of $\mathrm{CO}_{2}$ and $\mathrm{HCO}_{3}{ }^{-}$as the
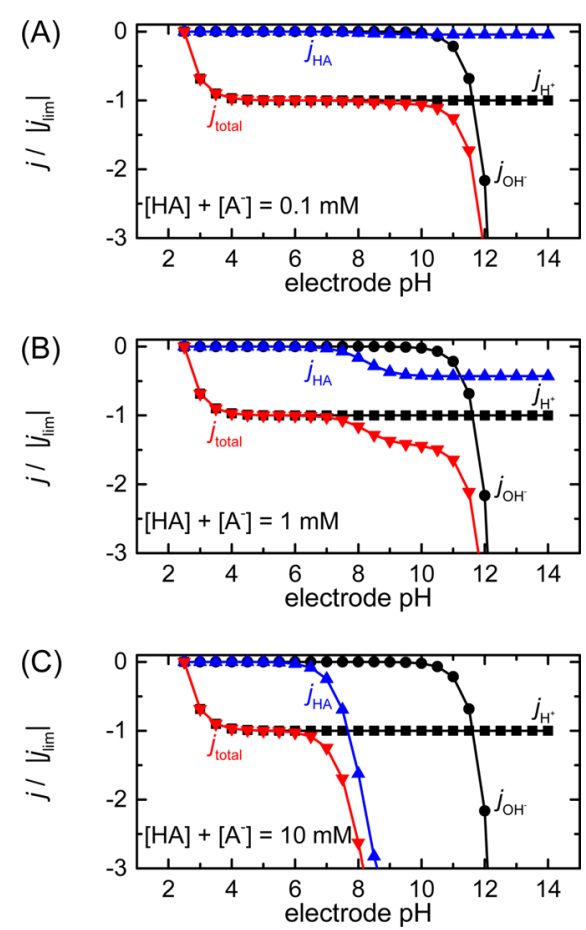

Figure 7. Estimation of the normalized current density based on the $\mathrm{pH}$ near the electrode surface ("electrode $\mathrm{pH}$ ") in a buffered solution with three different total buffer concentrations (A, $0.1 \mathrm{mM}$; B, $1 \mathrm{mM}$; and $\mathrm{C}, 10 \mathrm{mM}$ ). The contributions of the proton and hydroxide ion flux (black squares and circles, respectively) are the same as those in the unbuffered case. The total current density and the current density due to the flux of protons transported by $\mathrm{HA}$ are shown in red and blue triangles, respectively. Diffusion constants of $\mathrm{CO}_{2}$ and $\mathrm{HCO}_{3}{ }^{-}$ were used as the values for the protonated and deprotonated forms of the buffer molecule $\left(D_{H A}=1.47 \times 10^{-8}\left[\mathrm{~cm}^{2} / \mathrm{s}\right]\right.$ and $D_{A}=7.02 \times 10^{-9}$ $\left.\left[\mathrm{cm}^{2} / \mathrm{s}\right]\right) .{ }^{34}$ All other parameters are the same as those in Figure 6. 

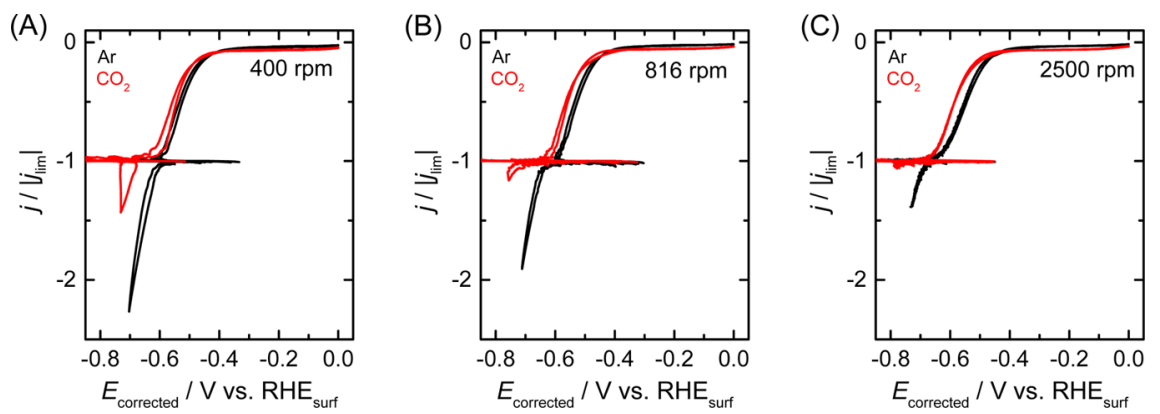

Figure 8. CVs after correcting for the local $\mathrm{pH}$ change at the electrode based on eqs 5 and 6 . Original experimental data are the same as those in Figure 2. Black lines, $\mathrm{Ar}$ atmosphere; red lines, $\mathrm{CO}_{2}$ atmosphere.

protonated and deprotonated forms of buffer molecule. When the buffer concentration is low compared to the proton concentration (panels A and B), the voltammogram resembles the unbuffered case. However, when the proton concentration and buffer concentration are within an order of magnitude (panels $\mathrm{B}$ and $\mathrm{C}$ ), the buffer molecule makes a noticeable contribution at surface $\mathrm{pH}>\mathrm{p} K_{\mathrm{a}}$. This can be understood by comparing the first and third terms (proton flux and buffer flux, respectively) of eq 12 . As maximum flux is attained when $[\mathrm{H}]_{b}$ $\gg[H]_{s}$ and $[H A]_{b} \gg[H A]_{s}$, the third term becomes significant when $\frac{D_{A} / D_{H}}{\delta_{A} / \delta_{H}} \frac{[A]_{b}}{[H]_{b}} \gg 1$.

In the case of an electrolyte in equilibrium with 1 atm of $\mathrm{CO}_{2}$, the concentration of carbonic acid $\left(\mathrm{H}_{2} \mathrm{CO}_{3}\right)$ is around 6 $\times 10^{-5} \mathrm{M}$, based on the hydration equilibrium constant ${ }^{35}$ $\left[\mathrm{H}_{2} \mathrm{CO}_{3}\right] /\left[\mathrm{CO}_{2}\right]=1.7 \times 10^{-3}$ and the solubility of $\mathrm{CO}_{2}(1.5 \mathrm{~g} /$ L). ${ }^{36}$ On the basis of the $\mathrm{p} K_{\mathrm{a}}$ of carbonic acid $\left(\mathrm{p} K_{\mathrm{a}}=3.6\right)$ and the diffusion coefficient of bicarbonate $7.02 \times 10^{-9}\left[\mathrm{~cm}^{2} / \mathrm{s}\right],{ }^{34}$ this would lead to $\frac{D_{A} / D_{H}}{\delta_{A} / \delta_{H}} \frac{[A]_{b}}{[H]_{b}}=0.00125 \ll 1$, indicating that the buffer capacity of $\mathrm{CO}_{2}$ is too small to play a role as a $\mathrm{pH}$ buffer in our results. This is in accord with the identical limiting current in the $\mathrm{CVs}$ before and after $\mathrm{CO}_{2}$ was introduced into the electrochemical cell (Figure 2). However, changing the electrolyte $\mathrm{pH}$ has marked consequences, as $[\mathrm{A}]_{\mathrm{b}}$ will increase simultaneously with the decrease of $[\mathrm{H}]_{\mathrm{b}}$. For example, $\frac{\mathrm{D}_{\mathrm{A}} / \mathrm{D}_{\mathrm{H}}}{\delta_{\mathrm{A}} / \delta_{\mathrm{H}}} \frac{[\mathrm{A}]_{\mathrm{b}}}{[\mathrm{H}]_{\mathrm{b}}}=1.25$ for a $\mathrm{CO}_{2}$-saturated solution at $\mathrm{pH} 4$, indicating that buffering effects from bicarbonate play a role at $\mathrm{pH}>4$.

On a more qualitative note, the results in Figure 7 show that in the presence of a $10 \mathrm{mM}$ buffer, the proton reduction current wave develops two plateaus, in agreement with the experimental results in Figure 1.

The lack of $\mathrm{pH}$ buffering effects from $\mathrm{CO}_{2}$ indicates that equations without explicitly taking buffering effects into account can be applied to $\mathrm{CO}_{2}$-saturated solutions. Specifically, eqs 56 can be used to calculate the local $\mathrm{pH}$ at the surface of the electrode during the CVs. Compared to Figure 2, which shows the current density with respect to the RHE at the bulk $\mathrm{pH}$, the $\mathrm{CVs}$ in Figure 8 show the normalized current density with respect to the RHE by correcting the potential $\left(E_{\text {corrected }}\right)$ using the $\mathrm{pH}$ existing at the electrode surface. The large horizontal noise near $\frac{j_{\text {total }}}{j_{\text {lim }} \mid}=-1$ is due to the large $\mathrm{pH}$ change $(4<\mathrm{pH}<$ $10)$, which amplifies the noise within the current density data from the original CV. The marked shift of the onset potential of water reduction compared to the original voltammogram is noteworthy. In the original CVs, proton reduction appeared to be favored over water reduction due to the $600 \mathrm{mV}$ smaller "apparent" overpotential. A large part of this is due to the difference between the bulk $\mathrm{pH}$ and the $\mathrm{pH}$ at the surface of the working electrode. However, there is still a $200 \mathrm{mV}$ difference in the onset potential even after correcting for the local $\mathrm{pH}$ change, indicating the activation energy for water reduction is larger than that of proton reduction. The larger activation energy for water reduction is in accord with previous HER studies on platinum in acid and alkaline electrolytes. ${ }^{22,23}$ Therefore, these studies highlight the importance of differentiating between the two HER pathways for discussing the competition with $\mathrm{CO}_{2}$ reduction.

\section{SUMMARY AND CONCLUSIONS}

In conclusion, the main $\mathrm{HER}$ pathway competing with $\mathrm{CO}_{2}$ reduction on a copper electrode was found to be water reduction, even in relatively acidic ( $\mathrm{pH}$ 2.5) electrolytes, where the proton reduction reaction is a diffusion-limited process hardly influenced by the presence of $\mathrm{CO}_{2}$ and $\mathrm{CO}$. We find that the water reduction pathway is specifically inhibited by adsorbed $\mathrm{CO}$ and that this "CO poisoning" leads to a high faradaic efficiency for $\mathrm{CO}_{2}$ reduction on copper electrodes. The inhibition of the HER pathway becomes more pronounced when the mass transport of $\mathrm{CO}_{2}$ is improved. Water reduction appears to be a slower process than proton reduction even after correcting for the $\mathrm{pH}$ change at the electrode. The different interactions with adsorbed $\mathrm{CO}$, along with the difference in overpotential, highlight the importance of differentiating between water reduction and proton reduction HER pathways.

\section{ASSOCIATED CONTENT}

\section{S Supporting Information}

The Supporting Information is available free of charge on the ACS Publications website at DOI: 10.1021/acs.langmuir.7b00696.

FTIR spectra showing the vibration region for bicarbonate and carbonate (PDF)

\section{AUTHOR INFORMATION}

\section{Corresponding Author}

*E-mail: m.koper@lic.leidenuniv.nl.

ORCID

Marc T. M. Koper: 0000-0001-6777-4594

Notes

The authors declare no competing financial interest. 


\section{ACKNOWLEDGMENTS}

We express our thanks to A. F. Beker and T. Mechielsen who fabricated the copper electrode, and to Dr. Ioannis Katsounaros for helpful discussions. H.O. received financial support from the Japan Society for the Promotion of Science (JSPS).

\section{REFERENCES}

(1) Qiao, J.; Liu, Y.; Hong, F.; Hong, F.; Zhang, J. A Review of Catalysts for the Electroreduction of Carbon Dioxide to Produce LowCarbon Fuels. Chem. Soc. Rev. 2014, 43, 631-675.

(2) Loiudice, A.; Lobaccaro, P.; Kamali, E. A.; Thao, T.; Huang, B. H.; Ager, J. W.; Buonsati, R. Tailoring Copper Nanocrystals towards $\mathrm{C}_{2}$ Products in Electrochemical $\mathrm{CO}_{2}$ Reduction. Angew. Chem., Int. Ed. 2016, 55, 5789-5792.

(3) Kortlever, R.; Shen, J.; Schouten, K. J. P.; Calle-Vallejo, F.; Koper, M. T. M. Catalysts and Reaction Pathways for the Electrochemical Reduction of Carbon Dioxide. J. Phys. Chem. Lett. 2015, 6, 4073-4082.

(4) Kas, R.; Kortlever, R.; Milbrat, A.; Koper, M. T. M.; Mul, G.; Baltrusaitis, J. Electrochemical $\mathrm{CO}_{2}$ Reduction on $\mathrm{Cu}_{2} \mathrm{O}$-derived Copper Nanoparticles: Controlling the Catalytic Selectivity of Hydrocarbons. Phys. Chem. Chem. Phys. 2014, 16, 12194-12201.

(5) Schouten, K. J. P.; Gallent, E. P.; Koper, M. T. M. The Influence of $\mathrm{pH}$ on the Reduction of $\mathrm{CO}$ and $\mathrm{CO}_{2}$ to Hydrocarbons on Copper Electrodes. J. Electroanal. Chem. 2014, 716, 53-57.

(6) Chen, C. S.; Handoko, A. D.; Wan, J. H.; Ma, L.; Ren, D.; Yeo, B. S. Stable and Selective Electrochemical Reduction of $\mathrm{CO}$ to Ethylene on Copper Mesocrystals. Catal. Sci. Technol. 2015, 5, 161-168.

(7) Kortlever, R.; Tan, K. H.; Kwon, Y.; Koper, M. T. M. Electrochemical Carbon Dioxide and Bicarbonate Reduction on Copper in Weakly Alkaline Media. J. Solid State Electrochem. 2013, 17, $1843-1849$.

(8) Kuhl, K. P.; Cave, E. R.; Abram, D. N.; Jaramillo, T. F. New Insights into the Electrochemical Reduction of Carbon Dioxide on Metallic Copper Surfaces. Energy Environ. Sci. 2012, 5, 7050-7059.

(9) Kuhl, K. P.; Hatsukade, T.; Cave, E. R.; Abram, D. N.; Kibsgaard, J.; Jaramillo, T. F. Electrocatalytic Conversion of Carbon Dioxide to Methane and Methanol on Transition Metal Surfaces. J. Am. Chem. Soc. 2014, 136, 14107-14113.

(10) Hori, Y.; Kikuchi, K.; Suzuki, S. Production of $\mathrm{CO}$ and $\mathrm{CH}_{4}$ in Electrochemical Reduction of $\mathrm{CO}_{2}$ at Metal Electrodes in Aqueous Hydrogencarbonate Solution. Chem. Lett. 1985, 14, 1695-1698.

(11) Hori, Y.; Kikuchi, K.; Murata, A.; Suzuki, S. Production of Methane and Ethylene in Electrochemical Reduction of Carbon Dioxide at Copper Electrode in Aqueous Hydrogencarbonate Solution. Chem. Lett. 1986, 15, 897-898.

(12) Lee, C. H.; Kanan, M. W. Controlling $\mathrm{H}^{+}$vs $\mathrm{CO}_{2}$ Reduction Selectivity on $\mathrm{Pb}$ Electrodes. ACS Catal. 2015, 5, 465-469.

(13) Ma, M.; Djanashvili, K.; Smith, W. A. Controllable Hydrocarbon Formation from the Electrochemical Reduction of $\mathrm{CO}_{2}$ over $\mathrm{Cu}$ Nanowire Arrays. Angew. Chem., Int. Ed. 2016, 55, 6680-6684.

(14) Tang, W.; Peterson, A. A.; Varela, A. S.; Jovanov, Z. P.; Bech, L.; Durand, W. J.; Dahl, S.; Norskov, J. K.; Chorkendorff, I. The Importance of Surface Morphology in Controlling the Selectivity of Polycrystalline Copper for $\mathrm{CO}_{2}$ Electroreduction. Phys. Chem. Chem. Phys. 2012, 14, 76-81.

(15) Durand, W. J.; Peterson, A. A.; Studt, F.; Abild-Pedersen, F.; Norskov, J. K. Structure Effects on the Energetics of the Electrochemical Reduction of $\mathrm{CO}_{2}$ by Copper Surfaces. Surf. Sci. 2011, 605, 1354-1359.

(16) Peterson, A. A.; Norskov, J. K. Activity Descriptors for $\mathrm{CO}_{2}$ Electroreduction to Methane on Transition-Metal Catalysts. J. Phys. Chem. Lett. 2012, 3, 251-258.

(17) Peterson, A. A.; Abild-Pedersen, F.; Studt, F.; Rossmeisl, J.; Norskov, J. K. How Copper Catalyzes the Electroreduction of Carbon Dioxide into Hydrocarbon Fuels. Energy Environ. Sci. 2010, 3, 13111315.

(18) Auinger, M.; Katsounaros, I.; Meier, J. C.; Klemm, S. O.; Biedermann, P. U.; Topalov, A. A.; Rohwerder, M.; Mayrhofer, K. J. J.
Near-Surface Ion Distribution and Buffer Effects During Electrochemical Reactions. Phys. Chem. Chem. Phys. 2011, 13, 16384-16394.

(19) Gupta, N.; Gattrell, M.; Bacdougall, B. Calculation for the Cathode Surface Concentrations in the Electrochemical Reduction of $\mathrm{CO}_{2}$ in $\mathrm{KHCO}_{3}$ Solutions. J. Appl. Electrochem. 2006, 36, 161-172.

(20) Kas, R.; Kortlever, R; Yilmaz, H.; Koper, M. T. M.; Mul, G. Manipulating the Hydrocarbon Selectivity of Copper Nanoparticles in $\mathrm{CO}_{2}$ Electroreduction by Process Conditions. ChemElectroChem 2015, $2,354-358$

(21) Sheng, W.; Gasteiger, H. A.; Shao-Horn, Y. Hydrogen Oxidation and Evolution Reaction Kinetics on Platinum: Acid vs Alkaline Electrolytes. J. Electrochem. Soc. 2010, 157, B1529-B1536.

(22) Ledezma-Yanez, I.; Wallace, W. D. Z.; Sebastian-Pascual, P.; Climent, V.; Feliu, J. M.; Koper, M. T. M. Interfacial Water Reorganization as a pH-Dependent Descriptor of the Hydrogen Evolution Rate on Platinum Electrodes. Nature Energy 2017, 2, 17031.

(23) Strmcnik, D.; Uchimura, M.; Wang, C.; Subbaraman, R.; Danilovic, N.; van der Vliet, D.; Paulikas, A. P.; Stamenkovic, V. R.; Markovic, N. M. Improving the Hydrogen Oxidation Reaction Rate by Promotion of Hydroxyl Adsorption. Nat. Chem. 2013, 5, 300-306.

(24) Jackson, M. N.; Surendranath, Y. Donor-Dependent Kinetics of Interfacial Proton-Coupled Electron Transfer. J. Am. Chem. Soc. 2016, $138,3228-3234$.

(25) Tu, C.; Tripp, B. C.; Ferry, J. G.; Silverman, D. N. Bicarbonate as a Proton Donor in Catalysis by $\mathrm{Zn}(\mathrm{II})$ - and $\mathrm{CO}(\mathrm{II})$ - Containing Carbonic Anhydrases. J. Am. Chem. Soc. 2001, 123, 5861-5866.

(26) Trummal, A.; Lipping, L.; Kaljurand, I.; Koppel, I. A.; Leito, I. Acidity of Strong Acids in Water and Dimethyl Sulfoxide. J. Phys. Chem. A 2016, 120, 3663-3669.

(27) Bard, A. J.; Faulkner, L. R. Electrochemical Methods Fundamentals and Applications, 2nd ed.; John Wiley and Sons: New York, 2001; p 339.

(28) Hori, Y.; Murata, A.; Takahashi, R.; Suzuki, S. Electroreduction of $\mathrm{CO}$ to $\mathrm{CH}_{4}$ and $\mathrm{C}_{2} \mathrm{H}_{4}$ at a Copper Electrode in Aqueous Solutions at Ambient Temperature and Pressure. J. Am. Chem. Soc. 1987, 109, $5022-5023$.

(29) Hori, Y.; Koga, O.; Yamazaki, H.; Matsuo, T. Infrared Spectroscopy of Adsorbed $\mathrm{CO}$ and Intermediate Species in Electrochemical Reduction of $\mathrm{CO}_{2}$ to Hydrocarbons on a $\mathrm{Cu}$ Electrode. Electrochim. Acta 1995, 40, 2617-2622.

(30) Hori, Y.; Murata, A.; Takahashi, R. Formation of Hydrocarbons in the Electrochemical Reduction of Carbon Dioxide at a Copper Electrode in Aqueous Solution. J. Chem. Soc., Faraday Trans. 1 1989, 85, 2309-2326.

(31) Wuttig, A.; Liu, C.; Peng, Q.; Yaguchi, M.; Hendon, C. H.; Motobayashi, K.; Ye, S.; Osawa, M.; Surendranath, Y. Tracking a Common Surface-Bound Intermediate during $\mathrm{CO}_{2}$-to-Fuels Catalysis. ACS Cent. Sci. 2016, 2, 522-528.

(32) Zhang, Y.-J.; Sethuraman, V.; Michalsky, R.; Peterson, A. A. Competition between $\mathrm{CO}_{2}$ Reduction and $\mathrm{H}_{2}$ Evolution on Transition-Metal Electrocatalysts. ACS Catal. 2014, 4, 3742-3748.

(33) Martinez-Hincapie, R.; Berna, A.; Rodes, A.; Climent, V.; Feliu, J. M. Surface Acid-Base Properties of Anion-Adsorbed Species at $\mathrm{Pt}(111)$ Electrode Surfaces in Contact with CO2-Containing Perchloric Acid Solutions. J. Phys. Chem. C 2016, 120, 16191-16199.

(34) Zeebe, R. E. On the Molecular Diffusion Coefficients of Dissolved $\mathrm{CO}_{2}, \mathrm{HCO}_{3}{ }^{-}$, and $\mathrm{CO}_{3}{ }^{2-}$ and their Dependence on Isotopic Mass. Geochim. Cosmochim. Acta 2011, 75, 2483-2498.

(35) Housecroft, C. E.; Sharpe, A. G. Inorganic Chemistry, 2nd ed.; Ashford Colour Press Ltd.: Essex, U.K., 2005; p 368.

(36) Dodds, W. S.; Stutzman, L. F.; Sollami, B. J. Carbon Dioxide Solubility in Water. Chem. Eng. Data Ser. 1956, 1, 92-95. 